\title{
Morphological monitoring of subtidal sponge assemblages
}

\author{
James J. Bell ${ }^{1, *}$, Mark Burton ${ }^{2}$, Blaise Bullimore ${ }^{2}$, Philip B. Newman ${ }^{2}$, Kate Lock $^{2}$ \\ ${ }^{1}$ Institute of Biological Sciences, University of Wales, Aberystwyth, Edward Llwyd Building, Aberystwyth, \\ Ceredigion SY23 3DA, UK \\ ${ }^{2}$ Skomer Marine Nature Reserve, Countryside Council for Wales, Fishermans Cottage, Martins Haven, Haverfordwest, \\ Pembrokeshire SA62 3BJ, UK
}

\begin{abstract}
The management of the marine environment requires effective temporal monitoring of communities and assemblages to detect any change above the level of natural variability. Even though sponges are usually abundant in subtidal hard substratum environments and have the ability to significantly influence other community members, they have often been excluded from monitoring programmes because they are taxonomically difficult and often hard to quantify compared to other marine groups. We consider the use of a morphological method to examine photoquadrat data collected at 3 hard substratum sites over a 10 yr period at Skomer Marine Nature Reserve, south-west Wales. Differences in the morphological assemblages and abundance were apparent between years, but the sponge assemblages showed rapid recovery (within $1 \mathrm{yr}$ ) to their original assemblage composition and abundance following declines. The changes were attributed to natural biological variation or a short-term impact, rather than any response to prolonged environmental change and there was no correlation between any of the changes in assemblages observed and the environmental variables measured. A comparison of morphological and species data enabled the same sponge assemblages to be identified at different sites, validating the method. This morphological approach to monitoring represents a cost-effective and realistic way of monitoring certain sponge assemblages.
\end{abstract}

KEY WORDS: Sponge $\cdot$ Morphology $\cdot$ Monitoring $\cdot$ Marine Nature Reserve

Resale or republication not permitted without written consent of the publisher

\section{INTRODUCTION}

Marine Protected Areas (MPAs) have been a key feature in the marine conservation effort throughout the world's oceans for many years (Kelleher \& Kenchington 1991). The effective management of these environments requires the monitoring of the communities and assemblages they protect to determine if change is occurring above the level of natural variability. An effective monitoring programme must be able to determine the nature (positive, negative or neutral) and rate of any change that might be occurring. Although a wide range of published material is available describing various monitoring methods (e.g. English et al. 1997, Davies et al. 2001), difficulty still lies in collecting data of suitable quality and quantity to detect change for most assemblages, while for many taxonomic groups monitoring methods have not been fully developed. There is still a need to develop reliable, cost-effective and realistic methods of data collection and analysis suitable for monitoring the marine environment.

Within the UK, the designation of Special Areas of Conservation (SAC), in response to the European Union Directive 92/43/EEC (Habitats Directive) has resulted in an increased need for effective monitoring of coastal and inshore areas (Brown et al. 1997). Although efforts have been made to develop approaches and methods to monitor marine environments, in most cases experimental evidence and longterm data to support these methods are not available (but see Davies et al. 2001). The best approach to characterising communities or assemblages when monitoring is to quantify all species present, but due to lack of 
resources, time and taxonomic expertise this approach is often limited or prohibited. This is particularly true of subtidal habitats where sampling time is restricted especially in the UK where considerable logistical support is required to comply with the 1997 Health and Safety Executive (HSE) diving regulations (HSE 1998).

Sponges are usually one of the dominant assemblages of hard substratum environments in temperate, tropical and polar regions (e.g. Dayton 1978, Hiscock 1983, Alvarez et al. 1990, Diaz et al. 1990, Bell \& Barnes 2000a, Bell \& Smith 2004). Despite the global importance of sponges they rarely feature to any great extent in benthic monitoring programmes. For example, even within the Great Barrier Reef monitoring programme, sponge abundance is recorded within a single category (Page et al. 2001). Sponges are known to be taxonomically difficult and it is often difficult to quantify their abundance compared to many other marine groups (e.g. molluscs, crustaceans, bryozoans and echinoderms), which probably accounts for their exclusion from most monitoring programmes (Wulff 2001). Even in the UK, where identification guides are readily available (e.g. Ackers et al. 1992), the lack of widespread specialist taxonomic expertise often limits the extent to which sponges can be identified. It is very important to monitor sponge assemblages, since this taxon has the ability to influence other benthic community members through competitive superiority (Bell \& Barnes 2003), their longevity (Ayling 1983) and the alteration of nearboundary flow regimes (Hiscock 1983). Thus, temporal and spatial variation in their abundance and assemblage composition is likely to have a considerable effect on other benthic community members.

A different potential approach to monitoring sponge assemblages is to consider temporal variation in the morphologies present, rather than using species abundance. Sponges are very morphologically diverse (Boury-Esnault \& Rützler 1997), with different morphologies predominating in different environmental regimes, particularly with respect to sedimentation and flow rate (Kaandorp 1999, Bell \& Barnes 2000b, Hill \& Hill 2002). Therefore, variation in environmental conditions could result in changes to the morphological composition of a sponge assemblage. Bell \& Barnes (2001, 2002) described a relationship between sponge species diversity and morphological diversity for tropical and temperate hard substratum sponge assemblages. This relationship demonstrated that the same differences in sponge assemblages, in response to different environmental regimes, could be identified whether morphological or species abundance data were used. The advantage of a morphological method of monitoring poriferan assemblages is that it requires no taxonomic training, just the ability to distinguish between different broad morphologies (e.g. encrusting and branching). The method also requires significantly less time and resources than the collection of species abundance data.

Skomer Marine Nature Reserve (MNR) in southwest Wales has an extensive, long-term monitoring programme encompassing a wide range of intertidal and subtidal habitats (Bullimore 1986). The monitoring of sponge assemblages was implemented in 1993 following anecdotal evidence of a decline in the abundance of some sponge species following local dredge-spoil dumping 5 miles west of St Anne's head (approximately $8 \mathrm{~km}$ from Skomer). These declines prompted a revision of dumping sites, resulting in post 1993 dumping occurring further offshore. Although the observed decline in sponges may have been caused by a number of factors, sedimentation is well known to influence sponge assemblages (Könnecker 1973, Bell \& Barnes 2000a). Skomer MNR sponge assemblages have been monitored for $10 \mathrm{yr}$ through the use of stereo photoquadrat techniques. Photographic monitoring allows a permanent record to be obtained and means large areas can be covered in a cost-effective way. The major drawback to this method lies in detecting community or assemblage changes because of identification problems, particularly when overlaying species or 3-dimensional forms are present. The aim of this study is to determine if changes in the assemblage structure of sponges can be identified from a long-term photographic data set using a morphological approach. The problems and advantages of using morphological data rather than species data are highlighted with respect to the monitoring of subtidal sponge assemblages.

\section{MATERIALS AND METHODS}

Study area. Skomer MNR is a statutory reserve designated in 1991 under the UK Wildlife and Countryside Act (1981). The reserve consists of 1500 ha of seabed sited off the Pembrokeshire coast (Fig. 1). Even before designation there was a long history of intensive subtidal marine biological surveys (see Bunker \& Hiscock 1984, 1985, 1987, Bunker et al. 1992). Sponge assemblages are monitored in the Thorn Rock area (Fig. 1), which is situated on the south side of Skomer Island and is open to the southwesterly swells (moderate exposure). Tidal currents only flow across this site for $3 \mathrm{~h}$ of the $12 \mathrm{~h}$ tidal cycle with speeds reaching 0.5 to $1 \mathrm{~m} \mathrm{~s}^{-1}$ on spring tides. Thorn Rock is predominantly igneous bedrock covered with silt to varying degrees and the subtidal turf in the area is dominated by bryozoans (e.g. Alcyonidium diaphaunum Lamouroux, Bugula spp.), 


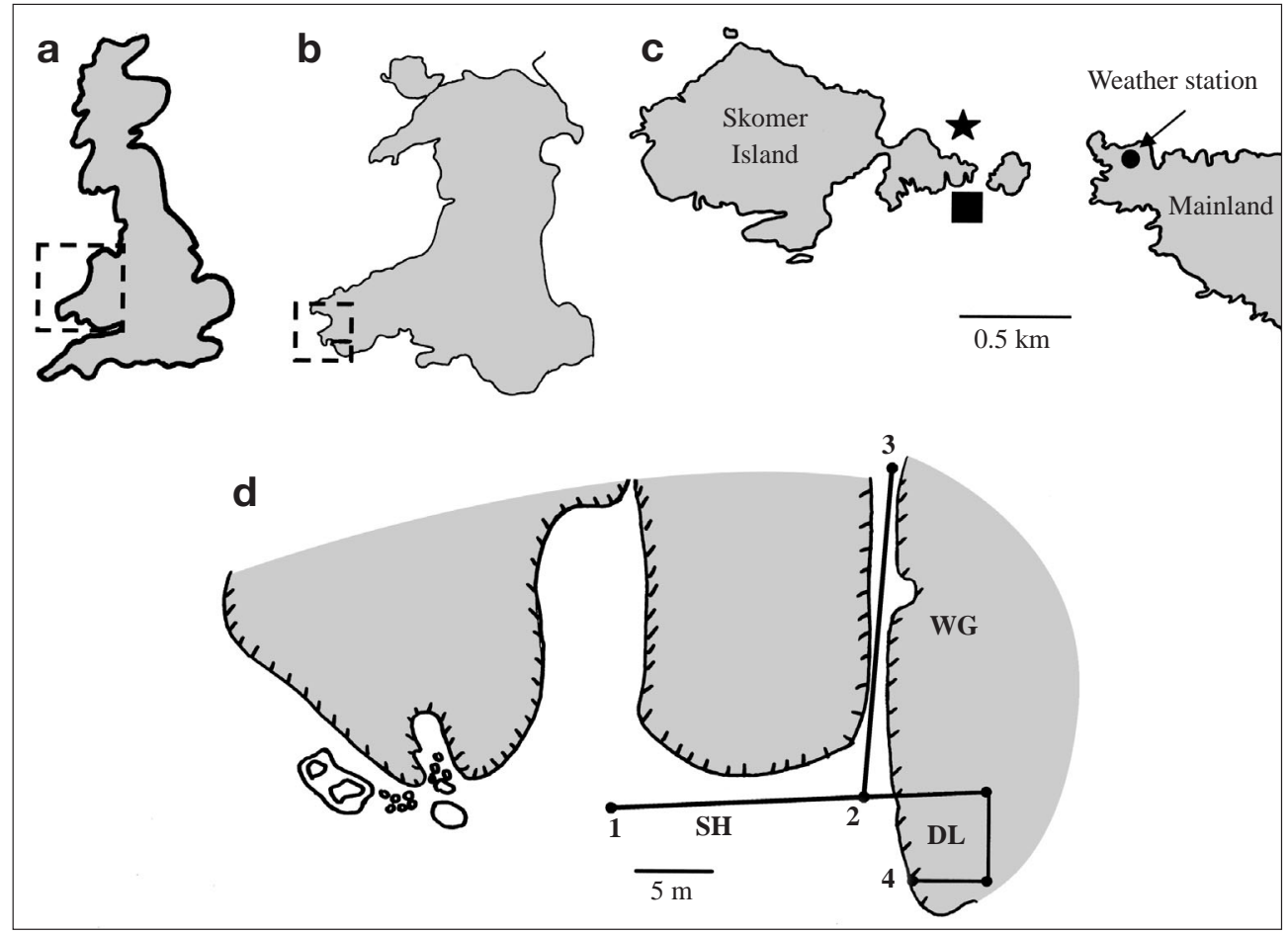

Fig. 1. Location where sponge assemblages were sampled at Skomer Marine Nature Reserve (MNR) at increasing magnification. (a) UK, (b) Wales, (c) Skomer Island and (d) sponge monitoring sites at Thorn Rock. ( $\star$ ) Subtidal environmental monitoring site, $(\bullet)$ weather station, (ם) the 3 study sites (Thorn Rock). WG: Windy Gulley; SH: Spongy Hillocks; DL: Dog Leg monitoring site

sponges and hydroids (Nemertesia spp.). Caryophyllia smithii Stokes \& Broderip is abundant along with anthozoans such as Coryonactis viridis Allman and Parazoanthus axinellae (Schmidt).

There are 3 sponge monitoring sites in the Thorn Rock area (Fig. 1). Windy Gulley (WG) is an inclined wall of bedrock at approximately $18 \mathrm{~m}$. The circumlittoral community is dominated by sponges and a hydroid/bryozoan turf. The sponge assemblage includes the massive form of Cliona celata Grant, Axinella dissimilis Schmidt, Stelligera spp. and Raspailia spp., along with more than 30 species of encrusting sponge. Spongy Hillocks ( $\mathrm{SH}$ ) is a horizontal area of bedrock reef at $18 \mathrm{~m}$ with many small ridges and gullies (1 $\mathrm{m}$ tall in places). Dominant sponge species include Hymeraphia stellifera Bowerbank, Polymastia spp., Raspailia spp., Stelligera spp. and Suberites carnosus (Johnston). The horizontal surface that runs across the top of the reef wall forming the WG site is the location of the Dog Leg monitoring site (DL) at $16 \mathrm{~m}$. There is an increased proportion of red algae amongst the sponges, hydroids and bryozoans at the DG site, with similar sponge assemblages to $\mathrm{SH}$.
Collection of morphological and species data. Morphological data were extracted from photographs obtained using stereo photography, with the total number of quadrats sampled at the 3 sites in the different years (1993 to 2003) shown in (Table 1). Two Nikonos cameras $(15 \mathrm{~mm}$ lens, $2 \times$ Ikelite 225 strobes, TTL, f/11, Velvia 50 ASA slide film) were attached to a metal photoquadrat to ensure the same camera to substratum distance and photographic angle was maintained between years, sites and quadrats. The area photographed was $0.35 \mathrm{~m}^{2}(0.7 \times 0.5 \mathrm{~m})$. A single transect was used at each site and photographs were taken at regular intervals along the transect. A tape was laid out between 2 fixed marker points and a site map with proforma was used to locate the same photoquadrat each year. Sampling was undertaken between August

Table 1. Number of quadrats sampled at the 3 sites over a $10 \mathrm{yr}$ period at Skomer Island. No sampling was undertaken during 1994 or 1999 due to lack of resources. See Fig. 1 for definition of site abbreviations

\begin{tabular}{|lccccccccc|}
\hline Site & 1993 & 1995 & 1996 & 1997 & 1998 & 2000 & 2001 & 2002 & 2003 \\
\hline WG & 25 & 31 & 31 & 20 & 30 & 31 & 29 & 31 & 31 \\
SH & 0 & 12 & 12 & 0 & 12 & 11 & 12 & 12 & 12 \\
DL & 5 & 21 & 21 & 0 & 18 & 21 & 21 & 21 & 20 \\
\hline
\end{tabular}


and September depending on local weather conditions. The slides were held $2 \mathrm{~cm}$ apart on a stereo viewer and observed through $\times 8$ loupes mounted $6 \mathrm{~cm}$ apart. This produced a 3D image that made the recognition and counting of erect sponges more reliable compared with 2D images. The number of each morphological type found within each quadrat was recorded from each image. The morphologies by which sponges were categorised in this study conformed to those described in the thesaurus of sponge morphology (Boury-Esnault \& Rützler 1997) and are illustrated in (Fig. 2). For encrusting forms, a sponge was included in the count if greater than $50 \%$ of its area occurred in the quadrat. Species data was only collected from WG $(\mathrm{n}=7)$ and $\mathrm{SH}(\mathrm{n}=9)$. The number of each sponge species found in each quadrat was recorded. Samples were taken for laboratory analysis for species that could not be identified in situ. Sponges were included in counts if greater than $50 \%$ of the sponge occurred in the quadrat.

Collection of environmental data. Wind speed, direction and rainfall data were collected by an automatic weather station located on Wooltack point (Fig. 1). The wind speed and direction was recorded every $3 \mathrm{~s}$ and logged as an average every $10 \mathrm{~min}$. The software logs average wind speed and maximum $3 \mathrm{~s}$ gusts. Rainfall was recorded with a tipping balance rainfall gauge, with totals logged every $10 \mathrm{~min}$. A Vemco mini-log sited at $19 \mathrm{~m}$ recorded the temperature every hour. Secchi disc readings were taken on a weekly basis using a $30 \mathrm{~cm}$ diameter disc connected to a Valeport series $600 \mathrm{MK}$ II CTD probe that recorded depth. A passive sediment trap was deployed at a subtidal monitoring station (Fig. 1) on a fixed frame at $19 \mathrm{~m}$. The sediment trap was a $1 \mathrm{~m}$ length of 4 inch (ca. $10.2 \mathrm{~cm}$ ) waste water pipe drilled with 2 inch (ca. $5.1 \mathrm{~cm}$ ) holes in the side and internal baffles. The sediment was collected in a pot at the base that was changed every 2 wk. The sediment sample was decanted and then frozen. Sediment samples were analysed for dry weight (dried at $60^{\circ} \mathrm{C}$ for $24 \mathrm{~h}$ ) between 1995 and 1998 (inclusive).

Statistical analysis. Morphological data were aggregated in some instances to reduce the problems associated with the identification of some morphologies from photographs. Arborescent (AR) and tubular forms (TU) were combined due to difficulty in confidently identifying TU forms. A Mann-Whitney $U$-test was used to compare the species richness between sites and abundance of sponges calculated from species data.

Ordination by non-metric Multi-Dimensional Scaling (MDS in PRIMER) was undertaken on a dissimilarity matrix created from Bray-Curtis similarity analysis to compare species assemblages between $\mathrm{SH}$ and

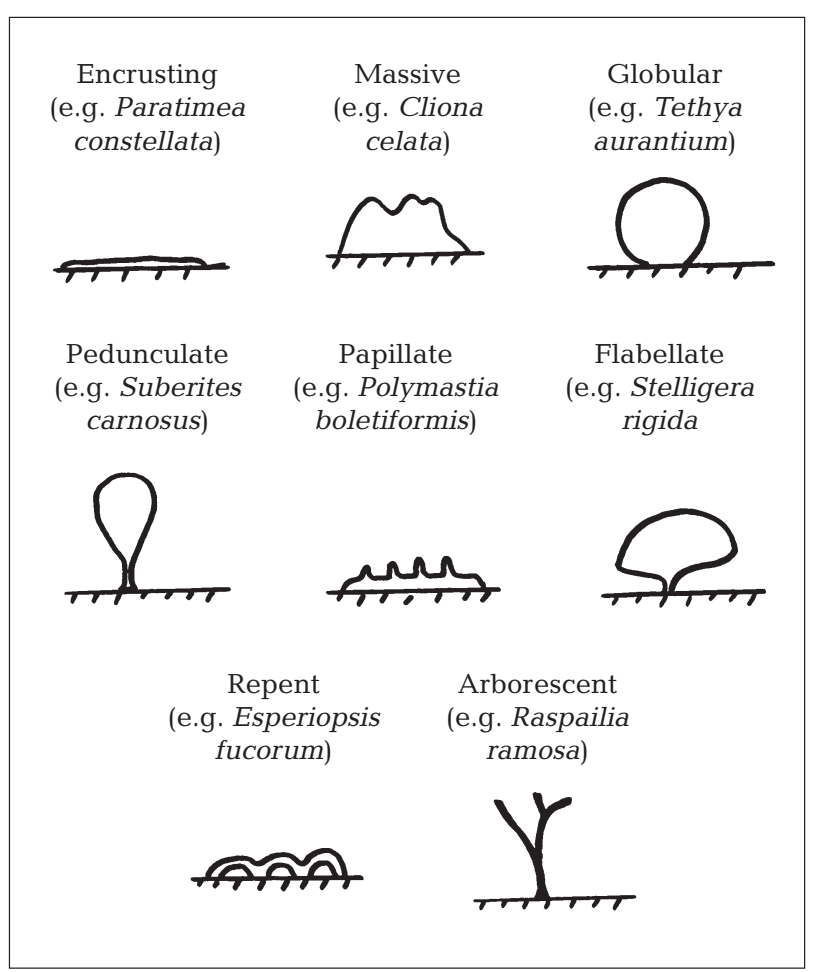

Fig. 2. Morphological groups to which sponges were assigned

WG, and morphological assemblages between years and sites. These matrices were calculated using hierarchical agglomerative group average clustering and the unweighted pair group method using arithmetic averages (UPGMA) with the PRIMER program (Plymouth Marine Laboratory). Species data were $\log (x+1)$ transformed to reduce the importance of rare species, while morphological data were square root transformed. SIMPER analysis (in PRIMER) was used to determine the contribution of each species to the average Bray-Curtis dissimilarity between $\mathrm{SH}$ and WG and was subjected to a $\log (x+1)$ transformation. This method determines which species are responsible for any differences that occur. Analysis of similarities (ANOSIM in PRIMER) was used to compare the morphological assemblages between years. The RELATE function in PRIMER was used to compare the BrayCurtis similarity matrices created to compare communities based on morphologies derived from photographs (between SH and WG) with matrices created by assigning species with their species-specific morphology from species diversity data. Pearson's correlation examined the relationship between Secchi depth and sedimentation rates. BIOENV (in PRIMER) was used to determine whether any correlation (Spearman's rank) existed between changes in the morphological community composition and the measured environmental variables. 


\section{RESULTS}

\section{Species composition and abundance}

A total of 34 and 43 sponge species was recorded from $\mathrm{SH}$ and WG respectively, with 57 species reported in total. Mean species richness $( \pm \mathrm{SE})$ was calculated as $17.43( \pm 1.43)$ sponges $\mathrm{m}^{-2}$ at $\mathrm{WG}$ and 14.22 $( \pm 0.78)$ sponges $\mathrm{m}^{-2}$ at $\mathrm{SH}$, although these differences were not significant (Mann-Whitney $W=73.5, \mathrm{p}=$ 0.15 , df $=15$ ) due to high between quadrat variability $(\mathrm{SH}$ median $=16, \mathrm{WG}$ median $=16)$. A plot constructed for cumulative species richness and area (cumulative quadrats) exhibited a logarithmic relationship at both sites showing that the majority of species within the study area were represented in the quadrats sampled (Fig. 3). At $\mathrm{SH}$ the most abundant species were Hymeraphia stellifera, Paratimea constellata Topsent, Polymastia boletiformis Lamarck, Raspailia/Stelligera juveniles, Stelligera stuposa Montagu and Suberites carnosus, while the most abundant species at WG included Plocamionida ambigua Bowerbank, Raspailia/ Stelligera juveniles, Dysidea fragilis (Montagu) and Halicnemia patera Bowerbank (Table 2). The abundance of sponges $( \pm \mathrm{SE})$, based on species data, was not significantly different between the 2 sites (MannWhitney $W=50.5, \mathrm{p}=0.37$, df = 15) with $197( \pm 17)$ and $235( \pm 27)$ sponges $\mathrm{m}^{-2}$ being found at $\mathrm{WG}$ and $\mathrm{SH}$ respectively.

Even though species richness did not vary significantly between the 2 sites, differences in species composition was apparent from the results of MDS (Fig. 4). There was clear separation between the 2 sites although there was considerable variability between individual quadrats. The results of ANOSIM showed these differences between sites to be significant $(R=$ 0.627, $\mathrm{p}=0.01,11440$ permutations). The species most responsible for these differences identified using SIMPER analysis were Plocamionida ambigua (6.1\%), Suberites carnosus (5.5\%), Paratimea constellata (5.5\%), Halicnemia patera (5.1\%), Hymeraphia stellifera $(4.5 \%)$ and Dysidea fragilis $(4.1 \%)$.

\section{Temporal variation in sponge abundance}

Although data were not available for sponge abundance based on in situ collection of species data over the study period, it was calculated from counting sponge morphologies recorded from the photographs. The number of sponges (Fig. 5) varied over the study period at each of the 3 sites. At WG a lower number of sponges was observed during 1995 and 2001 compared to all other years (Fig. 5). During 1995, the number of sponges $( \pm \mathrm{SE})$ at WG decreased from $87( \pm 4.9)$

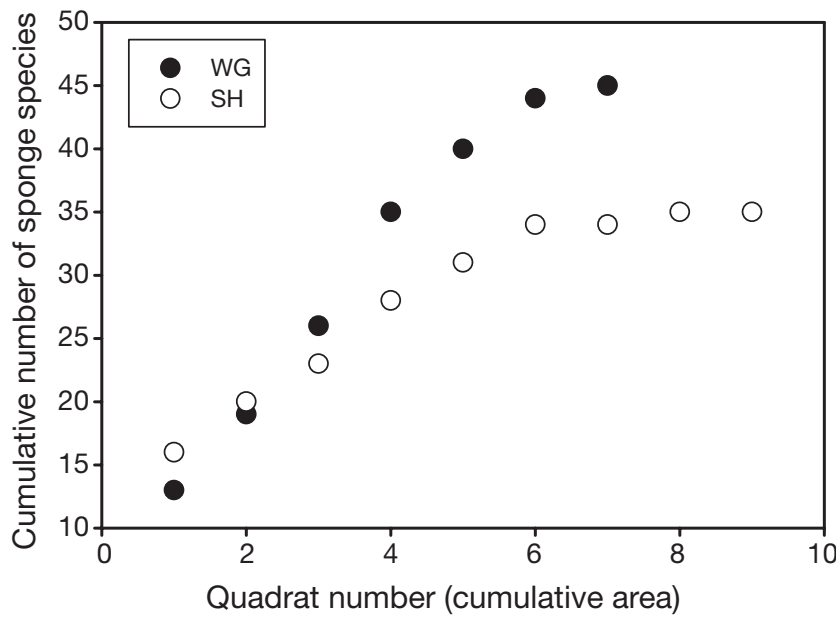

Fig. 3. Relationship between area sampled (cumulative quadrats) and species richness at 2 sites in Skomer MNR. See Fig. 1 for definition of site abbreviations

in 1993 to $38( \pm 4.2)$ sponges $\mathrm{m}^{-2}$ (note: no data for $1994)$, but then increased back to $80( \pm 3.3)$ sponges $\mathrm{m}^{-2}$ by 1996 . The density of sponges then remained relatively constant between 1996 and 2000, but decreased again at WG during 2001 to $68( \pm 4.3)$ sponges $\mathrm{m}^{-2}$, but did not fall to levels seen during 1995. During 2002 and 2003 sponge numbers then increased back to $99( \pm 5.2)$ sponges $\mathrm{m}^{-2}$ and remained constant. Sponge densities at DL varied very little over the study period with the only obvious difference occurring in 2003 when values were much higher than during all other years. At SH the only differences were observed when comparing sponge densities in 1995 with all other years. Sponge density increased from $51.5( \pm 6.0)$ sponges $\mathrm{m}^{-2}$ in 1995 to $89.6( \pm 5.4)$ sponges $\mathrm{m}^{-2}$ in 1996, but then showed little variability among the other time intervals.

\section{Temporal variation in different morphologies}

Only the numbers of some sponge morphologies varied considerably over the study period (Fig. 6). The number of arborescent sponges varied among time intervals at WG and SH (Fig. 6a) but not at DL. Lower numbers of arborescent sponges were observed during 1995 and 2001 at both WG and SH, although these time intervals differed very little between them. Arborescent forms decreased from approximately 40 to between 17 and 25 sponges $\mathrm{m}^{-2}$ during 1995 and 2001 at WG, while densities decreased from approximately 70 to between 40 and 46 sponges $\mathrm{m}^{-2}$ at $\mathrm{SH}$.

Pedunculate forms were not very abundant at WG (Fig. 6a), with less than 3 sponges $\mathrm{m}^{-2}$ being found in most years and little variation among years. At DL the 
numbers of pedunculate forms did decrease between 1993 and 1995 from 5 to $<3$ sponges $\mathrm{m}^{-2}$. However, the densities of this form remained low over the remaining time intervals $\left(<3\right.$ sponges $\left.\mathrm{m}^{-2}\right)$. At $\mathrm{SH}$, the number of pedunculate forms increased considerably over the study period, increasing from 3 to 17 sponges $\mathrm{m}^{-2}$, with the highest numbers being found during 2001.
Encrusting forms were much more abundant at WG than at the other 2 sites (Fig. 6b). At sites DG and SH, no difference was seen in the numbers of encrusting forms over the study period $\left(<3\right.$ sponge $\left.\mathrm{m}^{-2}\right)$. However, at WG some difference was observed in the numbers of encrusting forms between some pairs of years. Lower numbers were observed during 1995, while higher numbers

Table 2. Densities $( \pm \mathrm{SE})$ and morphologies $(\mathrm{M})$ of sponges $\left(\right.$ sponges $\left.\mathrm{m}^{-2}\right)$ found at 2 sites in Skomer Island $\mathrm{MNR}$. EN $=$ encrusting, $\mathrm{MA}=$ massive, $\mathrm{AR}=$ arborescent, $\mathrm{FL}=$ flabellate, $\mathrm{RE}=$ repent, $\mathrm{GL}=$ globular, $\mathrm{PA}=$ papillate, $\mathrm{PE}=$ pedunculate

\begin{tabular}{|c|c|c|c|}
\hline Species & M & Spongy Hillocks & Windy Gully \\
\hline Antho coriacea (Bowerbank, 1874) & EN & $0.31 \pm 0.31$ & 0 \\
\hline Antho inconstans Topsent 1925 & EN & 0 & $7.74 \pm 3.69$ \\
\hline Antho involvens (Schmidt, 1864) & EN & 0 & $1.23 \pm 0.86$ \\
\hline Axinella damicornis (Esper, 1974) & MA & 0 & $0.83 \pm 0.83$ \\
\hline Axinella dissimilis (Bowerbank, 1866) & AR & $1.91 \pm 0.94$ & $0.83 \pm 0.51$ \\
\hline Axinella infundibuliformis (Linnaeus, 1767) & FL & 0 & $1.17 \pm 1.17$ \\
\hline Biemnia sp. & MA & 0 & $0.40 \pm 0.40$ \\
\hline Chelonaplysilla sp. (de Laubenfels, 1948) & EN & 0 & $2.03 \pm 1.03$ \\
\hline Clathria armata (Bowerbank, 1866) & MA & 0 & $5.31 \pm 4.37$ \\
\hline Clathria atrasanguinea (Bowerbank, 1862) & EN & 0 & $3.69 \pm 3.69$ \\
\hline Clathrina lacunosa & $\mathrm{PE}$ & $0.63 \pm 0.43$ & 0 \\
\hline Clathria strepsitoxa (Carter \& Hope, 1889) & EN & 0 & $1.63 \pm 1.63$ \\
\hline Cliona celata (Grant, 1826) & MA & $2.23 \pm 1.03$ & 0 \\
\hline Dysidea fragilis (Montagu, 1818) & MA & $4.45 \pm 1.17$ & $22.9 \pm 3.37$ \\
\hline Esperiopsis fucorum (Esper, 1794) & EN & $2.54 \pm 1.6$ & $1.62 \pm 1.62$ \\
\hline Eurypon major Sara \& Siribelli, 1960 & EN & 0 & $3.26 \pm 1.57$ \\
\hline Eurypon sp. 1 & EN & $0.63 \pm 0.63$ & 0 \\
\hline Eurypon sp. 2 & EN & 0 & $0.83 \pm 0.83$ \\
\hline Halichondria panicea (Pallas, 1976) & MA & 0 & $0.83 \pm 0.51$ \\
\hline Haliclona cinerea (Grant, 1826) & MA & 0 & $1.23 \pm 0.86$ \\
\hline Haliclona fistulosa (Bowerbank, 1866) & $\mathrm{RE}$ & 0 & $0.83 \pm 0.51$ \\
\hline Haliclona oculata (Pallas, 1766) & AR & $0.94 \pm 0.49$ & $1.23 \pm 0.57$ \\
\hline Halicnemia patera Bowerbank, 1862 & EN & $2.23 \pm 1.03$ & $20.8 \pm 4.12$ \\
\hline Hemimycale columella (Bowerbank, 1866) & EN & $1.60 \pm 1.09$ & $2.80 \pm 1.40$ \\
\hline Homaxinella subdola (Bowerbank, 1866) & AR & $2.23 \pm 1.23$ & $2.46 \pm 1.14$ \\
\hline Hymedesmia jecusculum (Bowerbank, 1866) & EN & $3.17 \pm 1.67$ & $2.46 \pm 1.69$ \\
\hline Hymedesmia paupertas (Bowerbank, 1866) & EN & $0.31 \pm 0.31$ & $6.11 \pm 1.80$ \\
\hline Hymeniacidon perlevis (Montagu, 1818) & EN & $0.31 \pm 0.31$ & $1.62 \pm 1.62$ \\
\hline Hymeraphia stellifera Bowerbank, 1864, 1866 & EN & $54.6 \pm 15.9$ & $8.97 \pm 3.70$ \\
\hline Pachymatisma johnstonia (Johnston, 1842) & MA & 0 & $0.83 \pm 0.83$ \\
\hline Paratimea constellata (Topsent, 1893) & EN & $19.0 \pm 5.17$ & 0 \\
\hline Plocamilla coriacea (Bowerbank, 1874) & EN & 0 & $1.63 \pm 1.63$ \\
\hline Plocamionida ambigua (Bowerbank, 1866) & EN & $0.31 \pm 0.31$ & $21.2 \pm 5.40$ \\
\hline Polymastia boletiformis (Lamarck, 1813) & PA & $11.4 \pm 2.37$ & $4.89 \pm 1.74$ \\
\hline Polymastia mamillaris (Muller, 1806) & PA & $1.91 \pm 1.05$ & $1.23 \pm 0.57$ \\
\hline Polymastia sp. 1 & PA & 0 & $0.40 \pm 0.40$ \\
\hline Polymastia sp. 2 & PA & $0.31 \pm 0.31$ & 0 \\
\hline Pseudosuberites sulphureus (Bean in Bowerbank, 1866) & EN & $2.23 \pm 1.57$ & $4.09 \pm 1.74$ \\
\hline Raspacion aculeata (Johnston, 1842) & $\mathrm{AR}$ & $0.31 \pm 0.31$ & 0 \\
\hline Raspailia/Stelligera juveniles & $\mathrm{AR}$ & $73.9 \pm 7.11$ & $31.1 \pm 8.54$ \\
\hline Raspailia hispida (Montagu, 1818) & $\mathrm{AR}$ & $0.94 \pm 0.82$ & $2.46 \pm 1.31$ \\
\hline Raspailia ramosa (Montagu, 1818) & $\mathrm{AR}$ & $0.94 \pm 0.82$ & $4.08 \pm 1.23$ \\
\hline Raspailia virgultosa (Bowerbank, 1866) & $\mathrm{AR}$ & $0.31 \pm 0.31$ & 0 \\
\hline Stelligera rigida (Montagu, 1818) & $\mathrm{AR}$ & $3.49 \pm 1.48$ & 0 \\
\hline Stelligera stuposa (Montagu, 1818) & $\mathrm{AR}$ & $4.67 \pm 3.8$ & $9.80 \pm 2.63$ \\
\hline Suberites carnosus (Johnston, 1842) & $\mathrm{PE}$ & $19.1 \pm 4.77$ & $0.40 \pm 0.40$ \\
\hline Stylostichon dives (Topsent, 1891) & EN & 0 & $4.48 \pm 2.23$ \\
\hline Tethya aurantium (Pallas, 1766) & GL & $1.26 \pm 0.69$ & $1.63 \pm 1.23$ \\
\hline Tethyspira spinosa (Bowerbank, 1874) & MA & $1.26 \pm 0.69$ & 0 \\
\hline 8 unidentified species & EN & $3.23 \pm 1.66$ & $6.66 \pm 2.19$ \\
\hline
\end{tabular}


were seen during 2000, 2002 and 2003. The number of encrusting sponges observed in 2003 was higher than all other years. Papillate forms (Fig. 6b) showed no apparent difference in abundance over the study period at any of the 3 sites, with densities remaining between 3 and 8 sponges $\mathrm{m}^{-2}$. Massive forms (Fig. 6c) were much more abundant at WG compared to the other 2 sites. Lower numbers of sponges were observed at WG in 1995 and 2001 compared with other years. Also, the number of massive sponges appeared higher in 2003 compared to all other years. There was little difference among years at the other 2 sites.

\section{Temporal variation in morphological assemblage structure}

An MDS plot of sponge morphological assemblages at the different time intervals and at the different sites showed clear differences among some sites and years (Fig. 7), which was supported by the results of ANOSIM. There was clear separation on the MDS between WG and the other 2 sites, but little difference in the overall morphological assemblage composition between $\mathrm{SH}$ and DL. The most apparent difference among years could be seen during 1995, with the relationships being most obvious at WG and SH. ANOSIM results (Table 3) indicated a number of significant differences that were not obvious from the MDS plot. The sponge assemblages during 1995 were significantly different from all the other years at WG, but they were not significantly different to 1996 and 1998 at the other 2 sites. For the majority of the other differences among time intervals, the correlation coefficients were relatively low compared with correlations between 1995 and other years (Table 3). These differences in correlation coefficients were greater at WG than at the other sites, but the general pattern of higher coefficients between 1995 and

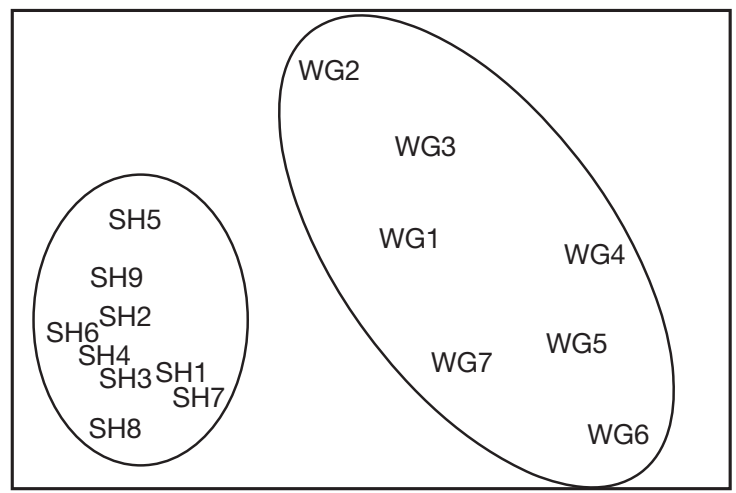

Fig. 4. Multi-dimensional scaling (MDS) plot of sponge assemblages at WG and $\mathrm{SH}$. Each point represents a single quadrat $(0.7 \times 0.5 \mathrm{~m})$. Stress $=0.1$. See Fig. 1 for definition of site abbreviations other years compared with other significant differences was found at all 3 sites. It was possible to track a number of sponges over the entire time period within individual quadrats (e.g. Cliona celata and Axinella dissimilis), while others were more ephemeral and only present over part of the series (e.g. Polymastia boletiforme). Recruitment events were also evident, particularly by arborescent sponges (e.g. Raspailia ramosa and Stelligera stuposa).

\section{Comparison of morphological data versus species data versus morphologically derived data}

An MDS plot constructed for the species data from WG and SH (Fig. 4) was compared with MDS plots

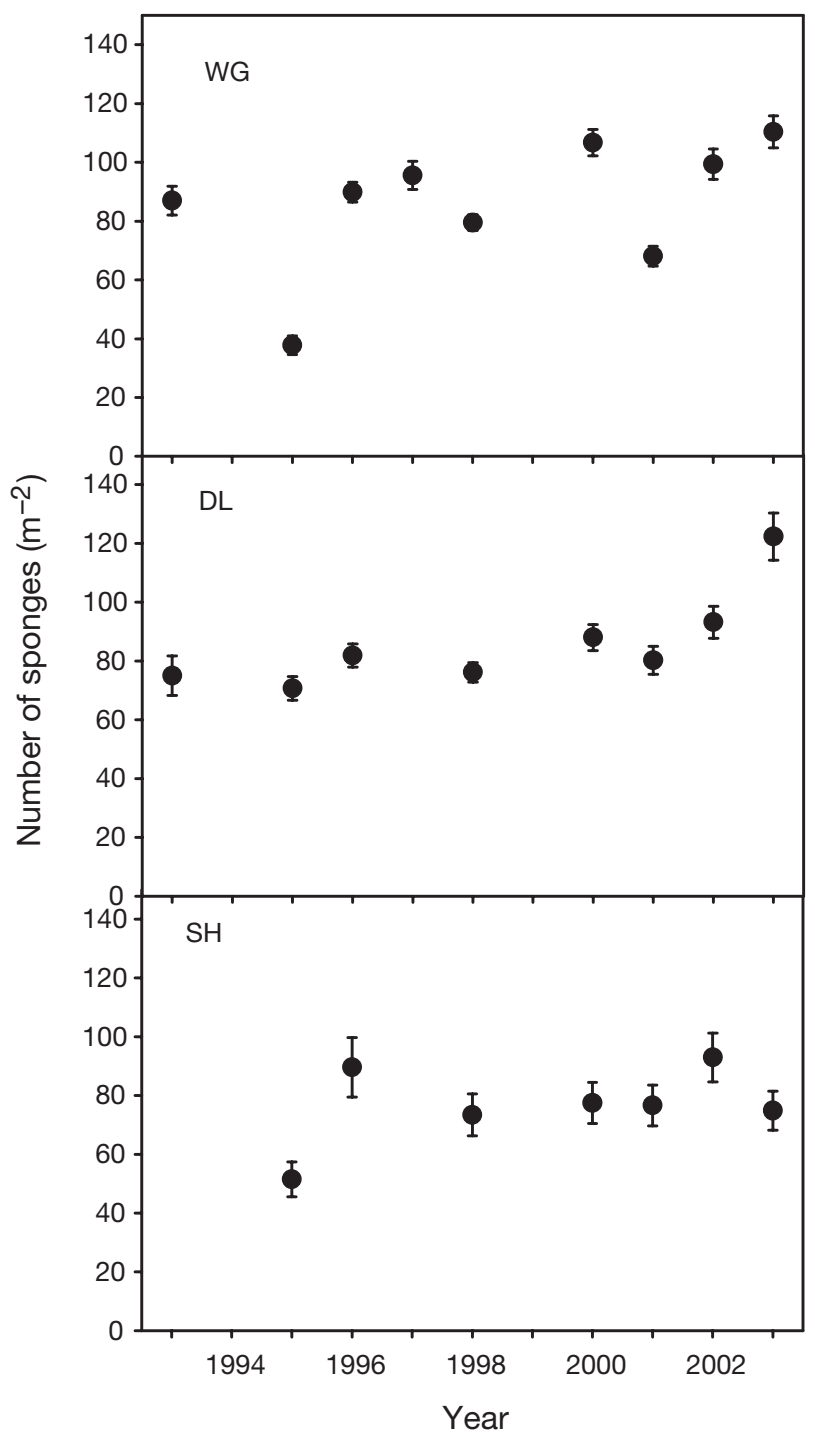

Fig. 5. Total abundance (number $\mathrm{m}^{-2}$ ) of sponges identified from photographs at 3 sites in Skomer MNR over a $10 \mathrm{yr}$ period. See Fig. 1 for definition of site abbreviations 

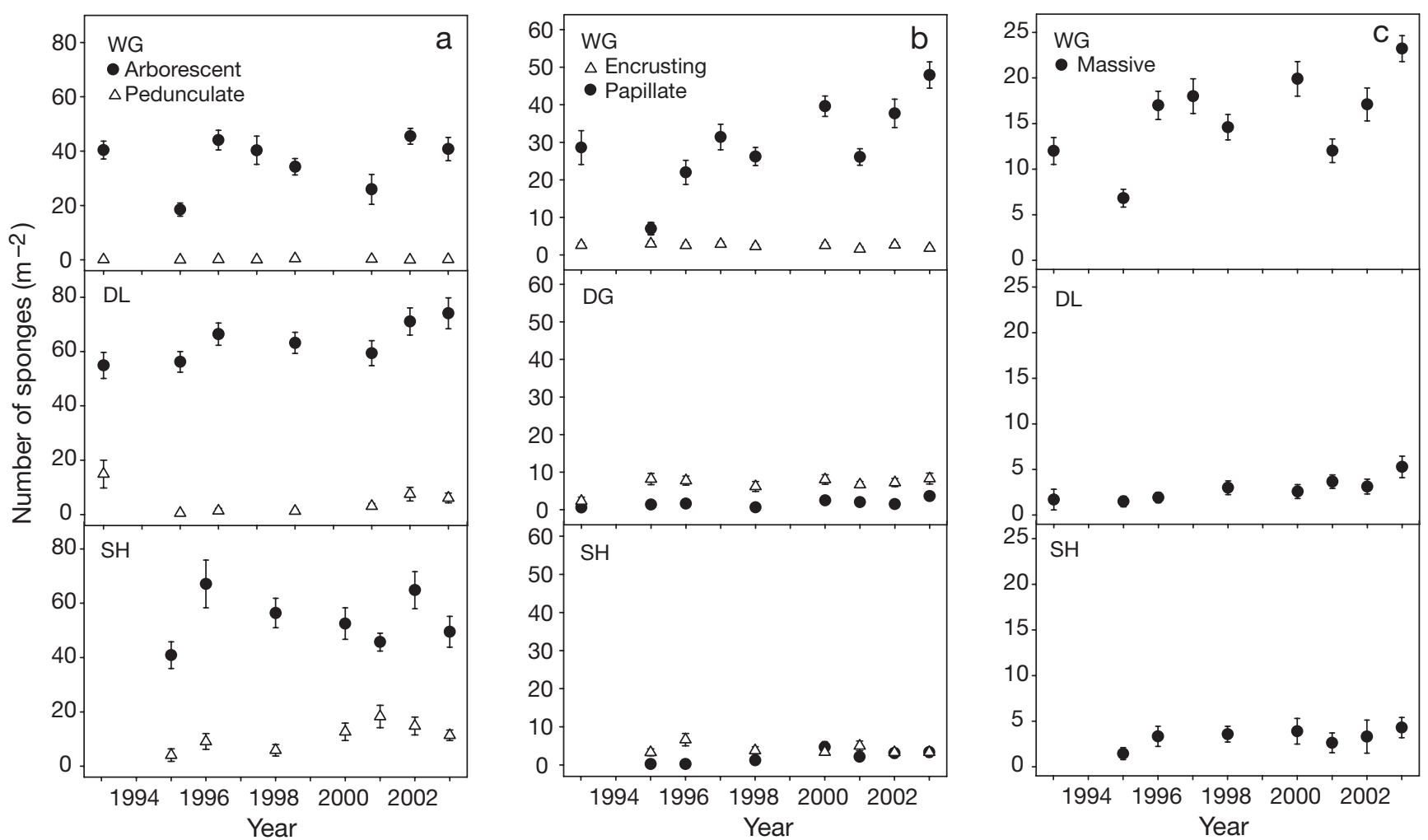

Fig. 6. Abundance (sponge morphologies $\mathrm{m}^{-2}$ ) of different sponge morphologies at 3 sites in Skomer MNR over a 10 yr period. See Fig. 1 for definition of site abbreviations

based on both morphologies assigned to species (from species data-plot not shown) and morphologies derived from photographs taken during 2003 (Fig. 7). The RELATE function (PRIMER), which compares the Bray-Curtis similarity matrices used to create MDS plots, showed that the matrices were not significantly different $(R>0.55$ at the 0.1 significance level). Therefore the same MDS patterns were apparent irrespective of the method used.

There was a large discrepancy between the total number of individuals identified from photographs (405 sponges) compared with those identified from in situ collection of sponge data (705 sponges) for the 2003 survey data. Of the species that were missed, encrusting sponges were the most important $(17.49 \pm$ 3.3 sponges missed per quadrat), which represented $45 \%$ of the total individuals observed. A high percentage of the total number of sponges (Fig. 8) was missed for most morphologies, although the actual numbers of most morphologies missed was low (<5 sponges). Only a small proportion of arborescent morphologies (14\%) was missed from photographs, mainly the small recent recruits. To test the effect of the large number of encrusting sponges missed, 2 similarity matrices were constructed of the morphological community composition (Bray-Curtis similarity) for WG and $\mathrm{SH}$ for all the different years, both with and with- out the encrusting data. The RELATE function (PRIMER) showed that the matrices were virtually identical $(R=0.907$ at the 0.1 significance level). Therefore, missing this large number of encrusting sponges made little difference to the patterns of morphological assemblage change identified between sites and years. The same was true for the other morphologies $(R>0.90$ at the 0.1 significance level).

\section{Environmental data}

Sedimentation data were only available between 1995 and 1998, so it was not possible to directly determine if this variable was responsible for any differences observed in the morphological community composition over the $10 \mathrm{yr}$ period. However, Secchi depth data was collected between 1995 and 2003 and the values obtained between 1995 and 1998 showed a strong significant $(R=-0.57, \mathrm{p}<0.01, \mathrm{df}=25)$ negative correlation with sedimentation rates. This suggests that Secchi depth may act as a suitable predictor of sedimentation rates, although it was very variable over the study period with no obvious patterns correlating with changes in morphological assemblage composition. The same was true for other measured variables, such as wind speed, including total wind, \% wind 
$>11 \mathrm{~m} \mathrm{~s}^{-1}$ and \% wind in ESW to WSW directions (onto the site), and rainfall (graphs not shown). Temperature (monthly averages between July and November) also showed considerable variability between years (graphs not shown) and no major differences were observed over the study period. BIOENV was used to determine any correlations between individual or combinations of environmental variables and the changes in assemblage composition between the different years. There were no strong correlations (Spearman's rank correlation coefficient $<0.40$ ) between the environmental data and the differences in morphological assemblages during the different years.

\section{DISCUSSION}

\section{Temporal changes in sponge morphological assemblages}

We found it was possible to identify temporal and spatial variation in the composition of sponge assemblages via the examination of morphologies, which represents an alternative approach to taxonomically based methods of sponge monitoring and is sensitive to assemblage change. The biggest change in sponges at Skomer MNR occurred during 1995, with a reduction in the overall number. Although there was some evidence for a morphological change in the sponge assemblages at $\mathrm{SH}$ and DL during that year, the greatest change was seen at WG. The similarities between SH and DL is not surprising given the similar topography and proximity of the 2 sites. The number of most morphological types decreased at WG during 1995 and 2001, but the sponge assemblages recovered

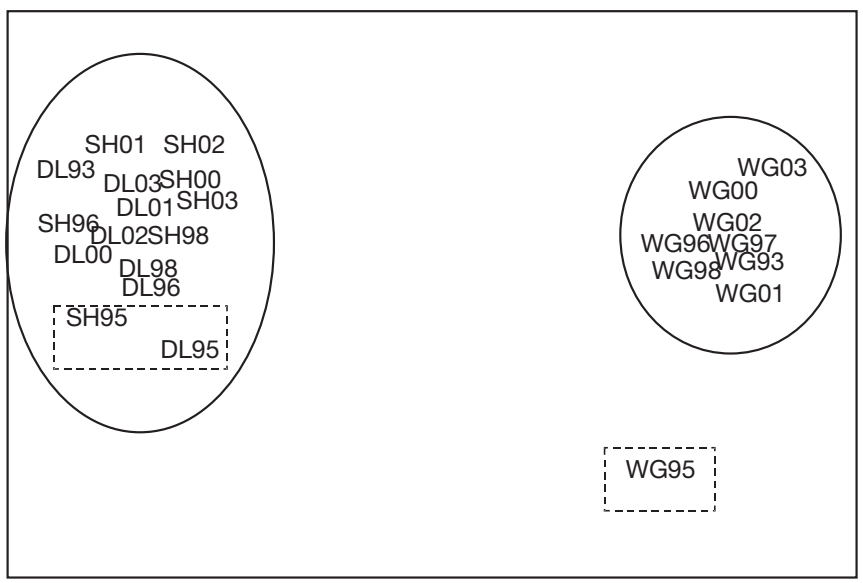

Fig. 7. MDS plot of the change in sponge morphology assemblage structure over a $10 \mathrm{yr}$ period in Skomer MNR. Solid lines: similarities between quadrats each site; dashed lines: a change in the assemblages during 1995. Stress $=0.1$. See Fig. 1 for definition of site abbreviations very quickly, with numbers increasing again the following year. Initially, photographs were carefully re-examined during 1995 and 2001 in case of misidentification of sponge morphologies or misalignment of permanent quadrats. It was found that these changes were not due to sampling errors, since it was possible to track individual sponges within quadrats which disappeared during 1995 and were replaced by new recruits in 1996. Although some differences in the temporal abundance of certain morphologies were identified between $\mathrm{SH}$ and $\mathrm{DL}$, the actual differences between the 2 sites were very small which is reflected by the similarity of the overall morphological assemblages.

Although some sponge species (e.g. Halichondria panicea and Hymeniacidon perlevis) are known to show rapid seasonal growth (Stone 1970, Thomassen \& Riisgård 1995) sponges are generally considered slowgrowing (Ayling 1983, Galera et al. 2000, Garrabou \& Zabala 2001) and late-colonisers of marine communities (Dayton 1978). The results of our study suggest that temperate sponge assemblages are more dynamic than previously thought, with many species and different morphologies showing a rapid decline in abundance, and subsequent recruitment and growth between sampling periods. There is evidence that sponge assemblages may change rapidly in response to anthropogenic impacts (Roberts et al. 1998), but the rapid reduction and subsequent recovery reported here is not characteristic of the general view that they are relatively stable over time. Pansini \& Pronzato (1990) reported very little change in sponge assemblages over a 6 yr period in the Mediterranean, with no evidence of yearly or seasonal cycles, which contrasts with the large change in Skomer sponge assemblages during 1995. There may be many reasons for the decrease in 1995 but it was not possible to identify any specific environmental or biological cause for the shift. The change seems unlikely to be a cause of concern from a conservation perspective because of the subsequent recovery of the sponge assemblages, but this event demonstrates the importance of describing patterns of biological variability over different temporal scales so that environmental managers can distinguish between natural variability, a short-term impact or a more significant impact.

\section{Skomer sponge assemblages}

The sponge assemblages at Skomer MNR are very diverse, with 57 species being reported, even though only approximately $5 \mathrm{~m}^{2}$ of rock surface was sampled in total. These are the first quantitative figures for sponge diversity on the Welsh coast. The diversity at 
this site is comparable with figures obtained for areas that are considered sponge biodiversity hotspots (Bell \& Barnes 2000a, Bell \& Smith 2004), even though the area sampled was considerably smaller (approximately 25 to $50 \mathrm{~m}^{2}$ in other studies). This demonstrates the importance of the Skomer MNR sponge assemblages. The species area curves did show a typical logarithmic relationship, suggesting that the majority of sponge species occurring on the sublittoral cliffs at Skomer MNR were detected. This also suggests that 7 to 10 quadrats (approx. $5 \mathrm{~m}^{2}$ ) is the optimal number required to effectively characterise the majority of the sponge biodiversity in these habitats.

The differences between WG and SH are most likely due to substratum angle, as this factor is well known to influence the species and morphological diversity of sponge assemblages (Bell \& Barnes 2000a,b,c,d, Bell \& Smith 2004). The microhabitat characteristics of WG (inclined surface) and SH (horizontal surface) will differ with respect to light availability, sediment settlement and accumulation rates, and abundance of some potential competitors (e.g. algae). Horizontal rock surfaces (SH) will have a greater abundance of macroalgae and higher sediment accumulation rates, accounting for the different assemblages.

Although a number of species were responsible for the differences between the WG and $\mathrm{SH}$ sites, those identified as the most important using SIMPER analysis were all encrusting (with the exception of Dysidea fragilis). This is not surprising because of the higher sediment accumulation rates on the horizontal surfaces at SH compared with the inclined surfaces at WG. This sediment may block the delicate sponge feeding apparatus (Hiscock 1983) and inhibit recruitment. Significantly lower numbers of arborescent forms were found on the inclined surfaces of WG compared to the other 2 sites. Arborescent forms are generally more common in areas experiencing higher rates of sedimentation in comparison to other morphologies, as these forms intercept a smaller amount of sediment per unit area (Chappell 1980, Bell \& Turner 2000). Bell \& Barnes (2000a) reported similar differences between vertical and inclined surface types at Lough Hyne, Ireland, but horizontal surfaces were not available for comparison. Raspailia ramosa and Stelligera stuposa represent the majority of arborescent specimens, with most examples exhibiting a single branched form, which are likely to be only several years old. Since the sponge sites experience strong wave and surge action during winter months and storms, the single branch forms, rather than multi-branch forms associated with low current sites, may be able to deal with this stress (see Bell \& Barnes 2000a). It is unlikely that this is an example of morphological adaptation, which is common in sponges (e.g. Palumbi 1986, Gaino et al. 1995), but rather an environmental constraint of moderate wave action.

\section{Problems and advantages of using a morphological method}

One of the biggest problems of a morphological approach to monitoring sponge assemblages identified in the present study was the number of sponges missed from photographic data. Even though a large proportion of the sponges were missed, the same assemblage differences could still be identified, giving confidence to our method. The loss of information is problematic,

Table 3. Results of ANOSIM (in PRIMER) to compare sponges assemblages based on morphologies over a $10 \mathrm{yr}$ period in Skomer MNR. (a) Site 1, Windy Gully, (b) Site 2, Spongy Hillocks, (c) = Site 3, Dog Leg. Values shown are Pearson's correlation $(R)$ coefficients calculated from permutation tests (in PRIMER), significant at ${ }^{*} 5 \%$ and ${ }^{* *}<1 \%$. Windy Gully Global $R=0.138$ significant at $0.1 \%$, Spongy Hillocks Global $R=0.088$ significant at $0.2 \%$, Dog Leg Global $R=0.1$ significant at $0.1 \%$

\begin{tabular}{|c|c|c|c|c|c|c|c|c|}
\hline $\mathbf{a}$ & 1993 & 1995 & 1996 & 1997 & 1998 & 2000 & 2001 & 2002 \\
\hline \multicolumn{9}{|l|}{1993} \\
\hline 1995 & $0.258^{* *}$ & & & & & & & \\
\hline 1996 & 0.01 & $0.336^{* *}$ & & & & & & \\
\hline 1997 & -0.019 & $0.293^{* *}$ & -0.036 & & & & & \\
\hline 1998 & 0.04 & $0.319^{* *}$ & 0.031 & -0.014 & & & & \\
\hline 2000 & $0.117^{* *}$ & $0.481^{* *}$ & $0.126^{* *}$ & 0.014 & 0.058 & & & \\
\hline 2001 & $0.092^{* *}$ & $0.276^{* *}$ & $0.134^{* *}$ & $0.079^{*}$ & 0.011 & 0.119 & & \\
\hline 2002 & 0.042 & $0.422^{* *}$ & $0.069^{* *}$ & -0.022 & 0.023 & -0.006 & $0.092^{* *}$ & \\
\hline 2003 & $0.206^{* *}$ & $0.583^{* *}$ & $0.165^{* *}$ & $0.086^{*}$ & $0.111^{*}$ & -0.003 & 0.222 & 0.014 \\
\hline b & 1995 & 1996 & 1998 & 2000 & 2001 & 2002 & & \\
\hline \multicolumn{9}{|l|}{1995} \\
\hline 1996 & $0.104^{*}$ & & & & & & & \\
\hline 1998 & 0.058 & -0.026 & & & & & & \\
\hline 2000 & $0.207^{* *}$ & 0.098 & 0.048 & & & & & \\
\hline 2001 & $0.242^{* *}$ & $0.167^{* *}$ & $0.161^{*}$ & -0.013 & & & & \\
\hline 2002 & $0.296^{* *}$ & 0.041 & 0.058 & -0.032 & 0.089 & & & \\
\hline 2003 & $0.287^{* *}$ & 0.049 & 0.036 & -0.024 & 0.076 & -0.067 & & \\
\hline c & 1993 & 1995 & 1996 & 1998 & 2000 & 2001 & 2002 & \\
\hline \multicolumn{9}{|l|}{1993} \\
\hline 1995 & $0.418^{* *}$ & & & & & & & \\
\hline 1996 & $0.471^{* *}$ & -0.009 & & & & & & \\
\hline 1998 & $0.338^{*}$ & 0.017 & 0.033 & & & & & \\
\hline 2000 & $0.258^{*}$ & $0.09^{*}$ & 0.022 & 0.037 & & & & \\
\hline 2001 & 0.088 & $0.139^{* *}$ & $0.075^{*}$ & 0.03 & -0.004 & & & \\
\hline 2002 & 0.112 & $0.135^{* *}$ & $0.069^{*}$ & 0.035 & -0.015 & -0.025 & & \\
\hline 2003 & $0.462^{* *}$ & $0.418^{* *}$ & $0.268^{* *}$ & 0.313 & $0.085^{*}$ & 0.065 & ** 0.047 & \\
\hline
\end{tabular}


but is likely to be the result of our current methodology. The majority of rock surfaces at Skomer MNR are covered in a fine layer of sediment, which covers many of the encrusting and low profile sponges preventing their identification in photographs (J. J. Bell unpubl. data). The removal of sediment from surfaces by 'wafting' prior to taking the photographs will reduce this effect in the future. As sponges appear to actively trap the sediment there is some concern that 'wafting' sediment from surfaces may change the local environment and negatively impact sponge assemblages. However, sediment removed from the surface of encrusting sponges is usually replaced within days and little impact is envisaged (J. J. Bell unpubl. data).

The collection of morphological data rather than sponge species data has received criticism from sponge ecologists (Bell \& Barnes 2001, 2002) because of the loss of ecological information. Yet this method is not intended to replace empirical studies of sponge assemblages, but aims to address the problem of monitoring areas where sponges predominate and taxonomic expertise or resources are not readily available. We still recommend species data be collected as well as morphological data, but at a different temporal scale and only after an initial assessment of the applicability of the method. It may be most appropriate to sample species data in response to changes identified in the morphological assemblage. Future research will focus on different scales of potential variability (e.g. inter-annual versus seasonal) to determine whether seasonal patterns of variability are also evident, since this will influence future sampling intervals.

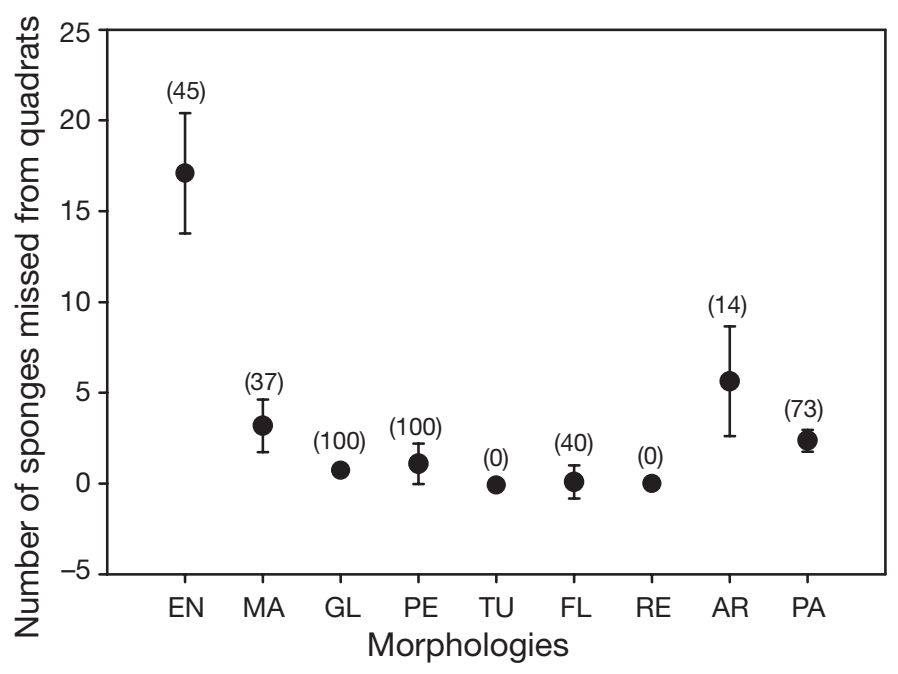

Fig. 8. Number of sponges from each morphological group missed from photographed quadrats, determined by comparing the abundance of each group from in situ data collection with that determined from photographs of the same area. Numbers in brackets indicate the percentage of the total missed
There may be limits to the type of habitat where a morphological assessment can be applied. Bell \& Barnes (2002) found the method to be unsuitable in tropical cave habitats, but data for temperate caves is currently unavailable. For some specialist habitats, such as caves or areas of very high current flow, morphological diversity may be very low, so it may be more appropriate for monitoring specific species. For example, current flow in the Menai Strait (North Wales, UK) is very fast due to local hydrodynamic conditions, and the massive form of Halichondria panicea dominates (Peattie \& Hoare 1981). The relationship between species diversity and morphological diversity was originally described for Lough Hyne MNR (Ireland) where the kelp zone is very much reduced, and all of the monitoring at Skomer MNR was conducted within the circumlittoral zone, where sponges dominate. It will be much more difficult to use this method in areas of dense kelp forest or dense algal coverage using photographic methods as the fronds are likely to interfere with the pictures. It also unclear whether a morphological approach will be applicable to these habitats because the 3-dimensional canopy structure may limit the development of many upright morphologies. The use of under water video rather than stills photography will be more suitable for assessing the sponge assemblages in macroalgal-dominated habitats.

It was not possible to correlate the changes in the sponge assemblages with any of the measured environmental variables, which is not surprising given the limited amount of environmental data available. Care must be taken when monitoring programmes are introduced to ensure adequate supporting environmental and biological data is collected to allow the causes of any change to be identified. More importantly, clear models and hypotheses need to be identified to determine exactly why monitoring is being undertaken and what the likely impacts of perceived threats are. Once threats are identified, experimental evidence of impacts are required as causality cannot be determined from correlative data. This is not only a problem in the current Skomer MNR monitoring programme, but also world-wide. Without good quality biological and environmental data, coupled with experimental evidence demonstrating causality, it is very difficult to identify potential causes of assemblage or community change. Studies of sponge assemblages suggest a number of physical factors control species distributions, including water flow rate (Bell \& Barnes 2000a), sedimentation (Könnecker 1973), nutrient levels (Storr 1976), depth (Alvarez et al. 1990, Witman \& Sebens 1990), light (Cheshire \& Wilkinson 1991) and habitat availability (Könnecker 1973, Barthel \& Tendal 1993). Biological factors can also influence the abundance and distribution of sponges (Wulff 1995, Dunlap \& Pawlik 1996). For example, benthic fish (e.g. wrasse) 
may inadvertently damage upright sponges while foraging and nest building and changes in their abundance might influence sponge abundance, particularly arborescent forms (Bell \& Barnes 2003). The wide range of potential factors that may influence benthic assemblages demonstrates that a comprehensive environmental monitoring programme must be initiated to complement biological monitoring.

The main drawback to the current sponge monitoring programme at Skomer MNR is the statistical limitations of the sampling design. Sponges are only sampled at one site, with no replication. This is due to the small overall size of Skomer and the large variability in environmental regimes over small spatial scales, which has caused problems for managers in locating suitable replicate sites. The transects and quadrats are also not independent of each other since transects meet (Fig. 1), which, combined with the lack of replication, limits an analysis of variance or non-parametric approach to data analysis (Underwood 1997). Therefore, it is not possible to draw statistically supported conclusions about changes in sponge abundance or specific morphological types over time. Replication and independence (both spatial and temporal) should be an important consideration in the establishment of any future sponge (or other assemblage) monitoring programme. This does not devalue the current multivariate approach to data analysis, which certainly demonstrates variation in sponge assemblages over time and between sites, but does limit the potential for examining changes in sponge abundance over time. In addition to the continued collection of the current morphological data at Skomer MNR, the programme will be modified to address these problems. Suitable replicate sites have recently been identified and permanent quadrats established. These quadrats will be used to examine seasonal and annual variability in sponge assemblages (at species and morphological level) in order to determine suitable future monitoring intervals, since current sampling intervals are primarily driven by the availability of resources to undertake the monitoring, rather than a biological justification. A final potential source of error is the method used to count morphologies, since sponges were included in counts only if $50 \%$ of the sponge fell within quadrats; however, this is difficult to avoid and is consistent with other studies of sponge assemblages (Bell \& Barnes 2000a,b).

An important advantage of considering assemblage change at the morphological level rather than by species composition is the cost-effectiveness of this method. Although monitoring changes in species abundance represents an ideal approach to monitoring sponges, in the majority of cases this is impractical for large areas of coastal habitats (e.g. SACs). The collec- tion of species data is expensive and resource consuming (approximately 40 times more expensive than morphology data) and is becoming increasingly difficult because of the decreasing number of taxonomic experts (Giangrande 2003). Rapid, effective and reliable methods are required to survey and monitor large benthic areas of hard substratum associated with the recent designation of SACs in the UK, although in most cases, resources for such monitoring are restricted. A morphological approach represents an alternative for monitoring sponge assemblages and is an important addition to the MPA monitoring toolkit.

Acknowledgements. We thank M. Camplin (Countryside Council for Wales, CCW) for initial statistical advice in the project and Dr. L. Luddington (CCW Skomer MNR) for fieldwork assistance. The authors are grateful to F. Bunker (MarineSeen) and J. Jones (MarineSeen) for the collection of sponge species data under CCW contract.

\section{LITERATURE CITED}

Ackers RG, Moss D, Picton BE (1992) Sponges of the British Isles (Sponge V). Marine Conservation Society, Ross-onWye

Alvarez B, Diaz MC, Laughlin RA (1990) The sponge fauna on a fringing coral reef in Venezuela, I: composition, distribution, and abundance. In: Rützler K (ed) New perspectives in sponge biology. Smithsonian Institute Press, London, p 358-366

Ayling AL (1983) Growth and regeneration rates in thinly encrusting demospongiae from temperate waters. Biol Bull (Woods Hole) 165:343-352

Barthel D, Tendal OS (1993) The sponge association of the abyssal Norwegian Greenland Sea: species composition, substrate relationships and distributions. Sarsia 78:83-96

Bell JJ, Barnes DKA (2000a) A sponge diversity centre within a marine island. Hydrobiologia 440:55-64

Bell JJ, Barnes DKA (2000b) The influence of bathymetry and flow regime on the morphology of sublittoral sponge populations at Lough Hyne MNR. J Mar Biol Assoc UK 80:707-718

Bell JJ, Barnes DKA (2000c) The distribution and prevalence of sponges in relation to environmental gradient within a temperate sea lough. Vertical cliff surfaces. Divers Distrib 6:283-303

Bell JJ, Barnes DKA (2000d) The distribution and prevalence of sponges in relation to environmental gradient within a temperate sea lough. Inclined cliff surfaces. Divers Distrib 6:305-323

Bell JJ, Barnes DKA (2001) The use of sponge morphological diversity as a qualitative predictor of species diversity. Aquat Conserv 11:109-121

Bell JJ, Barnes DKA (2002) Modelling sponges species diversity using a morphological predictor: a tropical test of temperate model. J Nat Cons 10:41-50

Bell JJ, Barnes DKA (2003) The importance of competitor identity, morphology and ranking methodology to outcomes in interference competition: an example of sponges. Mar Biol 143:415-426

Bell JJ, Smith D (2004) Ecology of sponges (Porifera) in the Wakatobi region, south-eastern Sulawesi, Indonesia: richness and abundance. J Mar Biol Assoc UK 84:581-591 
Bell JJ, Turner JR (2000) Factors influencing the density and morphometrics of the cup coral Caryophyllia smithii in Lough Hyne. J Mar Biol Assoc UK 80:437-441

Boury-Esnault N, Rützler K (1997) Thesaurus of sponge morphology. Smithsonian contributions to zoology 596. Smithsonian Institute Press, Washington, DC

Brown AE, Burn AJ, Hopkins JJ, Way SF (1997) The habitats directive: selection of special areas of conservation in the UK. JNCC Report 270. Joint Nature Conservation Committee, Peterborough

Bullimore B (1986) Skomer marine nature reserve subtidal monitoring project. Hydrobiologia 142:340

Bunker F, Hiscock S (1984) Surveys of sublittoral habitats and communities around Skomer Marine Reserve, 1983. Field Studies Council (OFC)/1/84. Nature Conservancy Council, Bangor

Bunker F, Hiscock S (1985) Surveys of sublittoral habitats \& communities around Skomer Marine Reserve in 1984. Field Studies Council (OFC)/2/85. Nature Conservancy Council, Bangor

Bunker F, Hiscock S (1987) Sublittoral habitats, communities and species around Skomer Marine Reserve-a review. Field Studies Council (OFC)/1/87. Nature Conservancy Council, Bangor

Bunker F, Picton B, Morrow C (1992) New information on species and habitats in Skomer MNR and other sites off the Pembrokeshire coast. Report to CCW. Countryside Council for Wales, Bangor

Chappell J (1980) Coral morphology, diversity and reef growth. Nature 286:249-252

Cheshire AC, Wilkinson CR (1991) Modelling the photosynthetic production by sponges on Davies Reef, Great Barrier Reef. Mar Biol 109:13-18

Davies J, Baxter J, Bradley M, Connor D and 5 others (2001) Marine monitoring handbook. Joint Nature Conservation Committee, Petersborough

Dayton PK (1978) Observations of growth, dispersal and population dynamics of some sponges in McMurdo Sound, Antarctica. In: Levi C, Boury-Esnault N (eds) Sponge biology. Colloq Int CNRS 291:271-282

Diaz MC, Alvarez B, Laughlin RA (1990) General features of Cuban sponge communities. In: Rützler K (ed) New perspectives in sponge biology. Smithsonian Institute Press, London, p 367-375

Dunlap M, Pawlik JR (1996) Video-monitored predation by Caribbean reef fishes on an array of mangrove and reef sponges. Mar Biol 126:117-123

English S, Wilkinson C, Baker V (1997) Survey manual for tropical marine resources. Australian Institute of Marine Science, Townsville

Gaino E, Maconi R, Pronzato R (1995) Organizational plasticity as a successful conservative tactic in sponges. Anim Biol 4:31-43

Galera J, Turon X, Uriz MJ, Becerro MA (2000) Microstructure variation in sponges sharing growth form: the encrusting sponges Dysidea avara and Crambe crambe. Acta Zool 81:93-107

Garrabou J, Zabala M (2001) Growth dynamics in four Mediterranean demosponges. Estuar Coast Shelf Sci 52:293-303

Giangrande A (2003) Biodiversity, conservation, and the 'taxonomic impediment'. Aquat Conserv 13:451-459
Hill MS, Hill AL (2002) Morphological plasticity in the tropical sponge Anthosigmella varians: Responses to predators and wave energy. Biol Bull (Woods Hole) 202:86-95

Hiscock K (1983) Water movement. In: Earll R, Erwin DG (eds) Sublittoral ecology. The ecology of the shallow sublittoral benthos. Clarendon Press, Oxford, p 58-96

HSE (Health and Safety Executive) (1998) Commercial diving projects inland/inshore. Diving at work regulations 1997. HSE books, London

Kaandorp JA (1999) Morphological analysis of growth forms of branching marine sessile organisms along environmental gradients. Mar Biol 134:295-306

Kelleher G, Kenchington R (1991) Guidelines for establishing marine protected areas. A marine conservation and development report. IUCN, Gland

Könnecker G (1973) Littoral and benthic investigations on the west coast of Ireland - I. (Section A: faunistic and ecological studies). The sponge fauna of Kilkieran Bay and adjacent areas. Proc R Ir Acad 73B(26):450-472

Page C, Coleman G, Ninio R, Osborne K (2001) Surveys of benthic reef communities using underwater video. Long-term monitoring of the Great Barrier Reef. Standard operational procedure number 7. Australian Institute of Marine Science, Townsville, available at www.aims.gov. $\mathrm{au} / \mathrm{pages} / \mathrm{research} /$ reef-monitoring/ltm/mon-sop7/3.pdf

Palumbi SR (1986) How body plans limit acclimation: responses of a demosponge to wave force. Ecology 67 : 208-214

Pansini M, Pronzato R (1990) Observations on the dynamics of a Mediterranean sponge community. In: Rützler K (ed) New perspectives in sponge biology. Smithsonian Institute Press, London, p 404-415

Peattie ME, Hoare R (1981) The sublittoral ecology of the Menai Strait. II. The sponge Halichondria panicea (Pallas) and its associated fauna. Estuar Coast Shelf Sci 13:115-142

Roberts DE, Smith A, Ajani A, Davis AR (1998) Rapid changes in encrusting marine assemblages exposed to anthropogenic point-source pollution: a 'Beyond BACI' approach. Mar Ecol Prog Ser 163:213-224

Stone AR (1970) Growth and reproduction of Hymeniacidon perlevis (Montagu) in Langston Harbour, Hampshire. J Zool 161:443-459

Storr JF (1976) Ecological factors controlling sponge distributions in the Gulf of Mexico and the resulting zonation. In: Harrison FW, Cowden RR (eds) Aspects of sponge biology. Academic Press, New York, p 261-276

Thomassen S, Riisgård HU (1995) Growth and energetics of the sponge Halichondria panicea. Mar Ecol Prog Ser 128: 239-246

Underwood AJ (1997) Experiments in ecology: their logical design and interpretation using analysis of variance. Cambridge University Press, Cambridge

Witman JD, Sebens KP (1990) Distribution and ecology of sponges at a subtidal rock ledge in the Central Gulf of Maine. In: Rützler K (ed) New perspectives in sponge biology. Smithsonian Institute Press, London, p 391-396

Wulff JL (1995) Sponge-feeding by the Caribbean starfish Oreaster reticulatus. Mar Biol 123:313-325

Wulff JL (2001) Assessing and monitoring coral reef sponges: why and how? Bull Mar Sci 69(2):831-816

Submitted: May 11, 2005; Accepted: September 20, 2005

Proofs received from author(s): March 10, 2006
Editorial responsibility: Roger N. Hughes (Contributing Editor), Bangor, UK 